\title{
Multi-batch Preparation of Standard Samples from a Single Doped Solution for Cross-checking in Surface Metal Analyses of Silicon Wafers
}

\author{
Yoshihiro MORI ${ }^{\dagger}$ and Kenichi Uemura \\ Advanced Technology Research Laboratories, Nippon Steel Corporation, clo NSC Electron Corporation, \\ 3434 Shimata, Hikari, Yamaguchi 743-0063, Japan
}

(Received May 1, 2000; Accepted June 1, 2000)

\section{Introduction}

Metallic impurities on semiconductor surfaces degrade the electrical properties of large-scale integrated circuits (LSIs). To determine such impurities, total reflection X-ray fluorescence spectrometry (TXRF) is widely used. ${ }^{1}$ TXRF requires reference standard samples for quantification. We have proposed a method for preparing standard samples for this purpose using immersion in an alkaline hydrogen peroxide solution (IAP)., ${ }^{2,3}$ In the IAP method, base silicon wafers are immersed in an alkaline hydrogen peroxide solution in which known amounts of metal ions are doped. The metal ions adsorb on the surface silicon dioxide layer. Since the metal adsorption is controlled by a natural equilibrium, ${ }^{4}$ the IAP wafers that are prepared in a single solution have high wafer-to-wafer uniformity. ${ }^{2}$ Because of this characteristic, the IAP wafers can also be used for crosschecking. ${ }^{5,6}$ However, the concentrations of the surface metal are not precisely the same between different production batches, even if the concentration of added metal is the same. This situation limits the maximum number of available identical wafers to 25 , which is the typical capacity of a wafer cassette. While the reason for such inconsistency is not clear, more than 25 identical samples are often required for large-scale crosscheck experiments. The aim of this paper is to propose an improved method of production that provides more than 25 identical IAP wafers.

\section{Experimental}

The silicon wafers used in the present work were $\mathrm{CZ}$ n-type single crystals with polished $\left(\begin{array}{lll}1 & 0 & 0\end{array}\right)$ faces. The wafers were cleaned with a $0.5 \%$ hydrofluoric acid solution (r.t., $2 \mathrm{~min}$ ), followed by a mixture of hydrochloric acid and hydrogen peroxide (standard cleaning solution-2: $\mathrm{SC}-2^{7}$ ) before the IAP process.

The baths for the IAP and rinse were made of high-purity quartz glass. That for the IAP was equipped with a circulation system. All apparatus that came into contact with either the wafers and/or the solutions were made of high-purity quartz glass or fluorocarbon polymer.

All chemicals, except for the metal solutions, were of

$\dagger$ To whom correspondence should be addressed.

E-mail: mori@re.nsc.co.jp semiconductor industry grade. The metal solutions were diluted standard solutions for chemical analysis.

The solution used for IAP was a 1:1:5 (volume ratio) mixture of $29 \% \mathrm{NH}_{3}, 31 \% \mathrm{H}_{2} \mathrm{O}_{2}$, and $\mathrm{H}_{2} \mathrm{O}$ (standard cleaning solution-1: $\left.\mathrm{SC}-1^{7}\right)$. A certain amount of $\mathrm{Fe}$ and $\mathrm{Ni}$ solution was added to the solution. After all the chemicals were poured into the bath, the solution was circulated for $5 \mathrm{~min}$ to become homogeneous. The pre-cleaned wafers were then immersed for $120 \mathrm{~s}$ at $60^{\circ} \mathrm{C}$, followed by a quick dump rinse bath (QDR, $180 \mathrm{~s}$ ), and then an overflow bath (OFR, $270 \mathrm{~s}$ ). The wafers were finally dried with a spindrier (SPD, $600 \mathrm{rpm}, 270 \mathrm{~s}$ ). The timetable is shown in Fig. 1.

The $\mathrm{NH}_{3}$ and $\mathrm{H}_{2} \mathrm{O}_{2}$ concentrations were monitored with a continuous-flow spectrophotometric analyzer (CS-220, COS Ltd. ) every $5 \mathrm{~min}$.

The adsorbed metal concentration was measured with TXRF (TXRF300, Rigaku corp.). The excitation X-ray was Au- $\mathrm{L}_{\beta}$

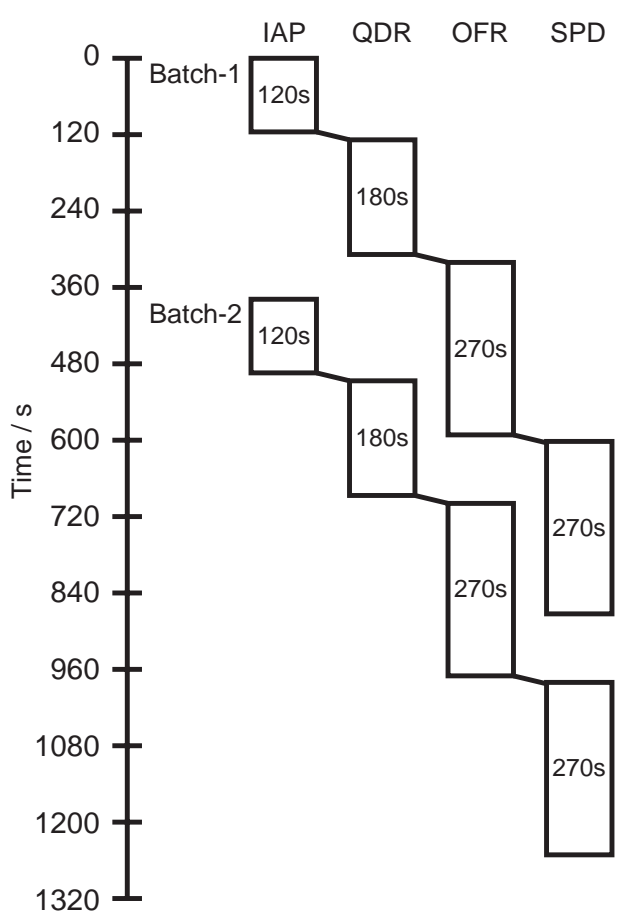

Fig. 1 Timetable of the multi-batch IAP processing conducted in the present study. 


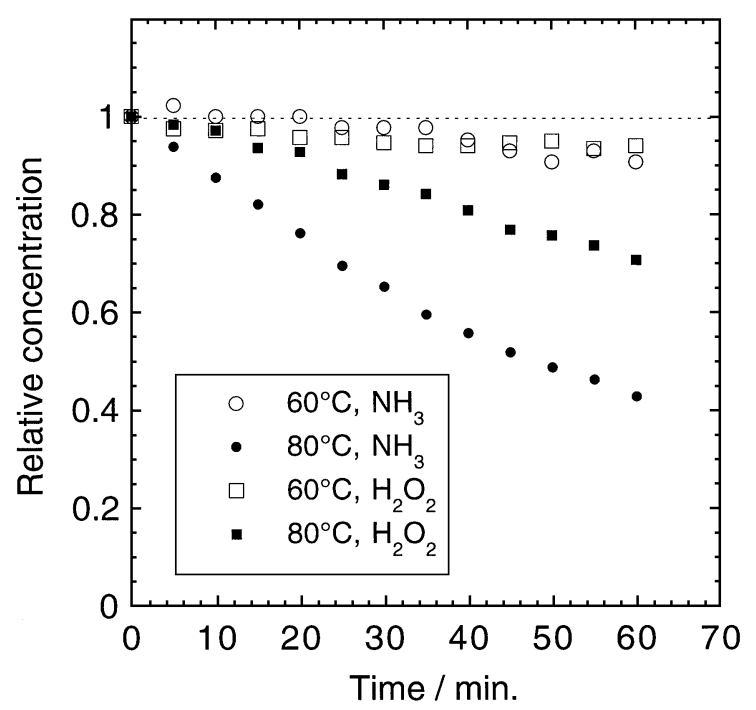

Fig. 2 Time-dependent decrease of the chemical concentration for ammonia and hydrogen peroxide.

(11.44 keV). The applied voltage was $35 \mathrm{kV}$ and the current was $255 \mathrm{~mA}$. The measuring glancing angle was $0.08 \mathrm{deg}$. and the integration time was $500 \mathrm{~s}$ for each point. The measuring points were $(0,0),(45,45)$, and $(-45,-45)$ under a notch-down $x-y$-coordinate. The data for each wafer was averaged so as to evaluate the wafer-to-wafer uniformity. Nine-point mapping measurements were also conducted for some wafers to evaluate the surface uniformity.

\section{Results and Discussion}

To achieve the purpose of this research, we improved the previous IAP procedure in two ways. One was to reuse a single solution for more than one cassette of wafers. Here, we discuss the adsorption of nickel in SC-1 solution. Ni is usually chosen as a standard element because of its stability and the low probability of unintentional contamination. When 25 silicon wafers are immersed in a $30 \mathrm{dm}^{3} \mathrm{SC}-1$ solution containing $\mathrm{Ni}$, for example, the equilibrium atomic ratio of the total surface $\mathrm{Ni}$ against the total dissolved $\mathrm{Ni}$ is calculated to be only $2.6 \times 10^{-4}$. This means that the dissolved $\mathrm{Ni}$ concentration after the immersion of 25 wafers is almost the same as that before immersion. Thus, it may be possible to produce cassettes of almost identical IAP wafers by immersing them in the same solution sequentially. The other improvement is a reduction in the solution temperature. The composition of SC-1 solution changes over time, shifting the $\mathrm{pH}$ so that the metal adsorption behavior varies. Because the composition change is primarily caused by the vaporization of $\mathrm{NH}_{3}$, the change is highly related to the solution temperature. ${ }^{8}$ For conventional IAP, in which the solution temperature is $80^{\circ} \mathrm{C}$, the chemical concentration of the solution decreases very rapidly, as shown in Fig. 2. Such a change influences the adsorption behavior between different batches, even if the same SC-1 solution is used sequentially. Reducing the temperature is effective for avoiding a compositional shift. Because it is known that silicon dioxide, where the metal ions adsorb, can be formed in less than $1 \mathrm{~s}$ even if the solution temperature is reduced to $23^{\circ} \mathrm{C},{ }^{9}$ we tested lowtemperature SC-1. In Fig. 2, data for $60^{\circ} \mathrm{C} \mathrm{SC}-1$ is also plotted. At that temperature, the variation in the $\mathrm{SC}-1$ composition is

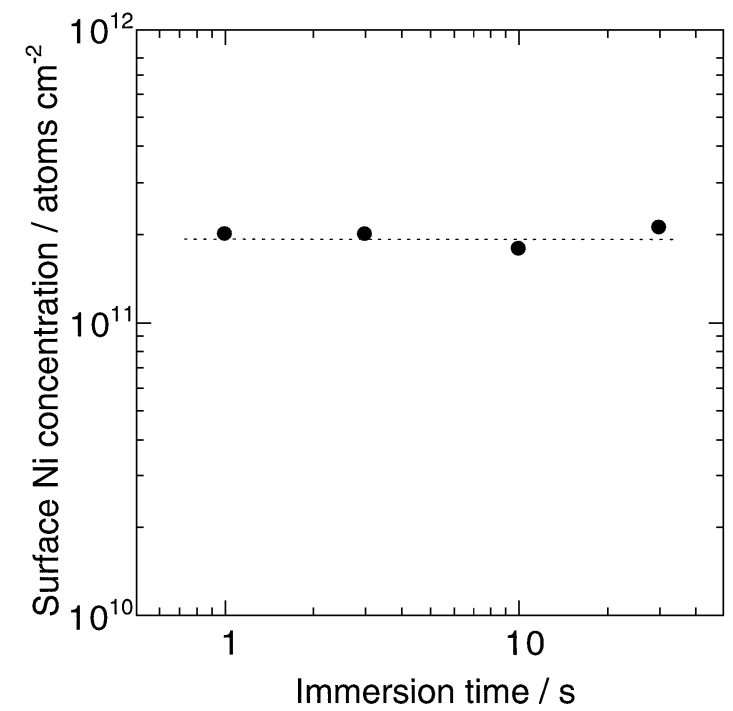

Fig. 3 Time dependence of nickel adsorption onto silicon wafers in SC-1 solution.

Table 1 Statistical table of the wafer-to-wafer uniformity for iron and nickel

\begin{tabular}{clcc}
\hline & & $\mathrm{Fe}$ & $\mathrm{Ni}$ \\
\hline Batch-1 & Average concentration/atoms cm ${ }^{-2}$ & $4.90 \times 10^{10}$ & $1.11 \times 10^{10}$ \\
(25 wafers) & Wafer-to-wafer uniformity & 6.7 & 19.0 \\
& as CV \% & & \\
& Average fluorescence/cps & 0.331 & 0.114 \\
& Theoretical statistical error & 5.4 & 9.6 \\
& $(1 \sigma)$ as CV \% & & \\
Batch-2 & Average concentration/atoms cm ${ }^{-2}$ & $5.07 \times 10^{10}$ & $1.13 \times 10^{10}$ \\
$(25$ wafers $)$ & Wafer-to-wafer uniformity & 5.3 & 13.1 \\
& as CV \% & & \\
& Average fluorescence/cps & 0.342 & 0.116 \\
& Theoretical statistical error & 5.3 & 9.5 \\
& $(1 \sigma)$ as CV \% & & \\
\hline
\end{tabular}

negligible over some ten-minutes' period. Because the practical time required for IAP processing is several minutes per batch, and further because the required time to reach the adsorption equilibrium is less than $1 \mathrm{~s}$ (Fig. 3), multi-batch processing of IAP is easily achieved within the above-mentioned period. Based on these facts, the multi-batch experiment in this study was actually accomplished by following the timetable shown in Fig. 1.

Statistical summaries of the wafer-to-wafer uniformity are listed in Table 1. As for $\mathrm{Fe}$, the uniformity in each batch was below $10 \%$ in a coefficient of variation (CV\%) scale, which is within the typical values for IAP wafers. ${ }^{2}$ In contrast, the CV\% of $\mathrm{Ni}$ was slightly large. However, because certain parts of the dispersion came from the inherent statistical variation of fluorescence, the actual uniformity is considered to be satisfactory for cross-check use. The average concentrations of the two batches were almost the same for both Fe and Ni. To check whether the difference was significant, we ran a Student's $t$ test for the null hypothesis that any difference is caused by only random errors. ${ }^{10}$ The results are summarized in Table 2. The values of $t$ do not exceed the 5\% level of significance for both $\mathrm{Fe}$ and $\mathrm{Ni}$, meaning that there is no basis for rejecting the above hypothesis. This means that the two batches can be used 
Table 2 Results of a test of the significance (Student's $t$ ) at the 5\% level between the first and second batch

\begin{tabular}{lcc}
\hline & $\mathrm{Fe}$ & $\mathrm{Ni}$ \\
\hline $\begin{array}{l}\text { Absolute value of } t \\
\text { Critical value of } t \text { (confidence interval }=95 \%)\end{array}$ & 1.95 & 0.29 \\
\hline
\end{tabular}

as though the 50 wafers were fabricated in a single batch Furthermore, from the data showing that the composition shift at $60^{\circ} \mathrm{C}$ is very small within some ten-minutes' (Fig. 2), more than 50 identical wafers (i.e. more than two cassettes) can be produced with this method.

Mapping measurements were performed for some wafers to evaluate the uniformity of the concentration on the surface. The statistical list is given in Table 3. For Fe, the uniformity is almost the same as the previous data of single-batch IAP. ${ }^{2}$ The $\mathrm{CV} \%$ for $\mathrm{Ni}$ is nearly $20 \%$, but the inherent statistical variation of fluorescence may contribute to the large dispersion because of the low fluorescent intensity (Table 1); thus, the actual uniformity is considered to be satisfactory.

\section{Acknowledgements}

The authors wish to acknowledge Dr. R. S. Hockett (Charles Evans \& Associates) for his pertinent suggestions. The authors also thank the members of ISO/TC201/WG2 for their helpful discussion

\section{References}

1. R. S. Hockett, Adv. X-ray Anal., 1994, 37, 565.
Table 3 Uniformity of the surface metal concentration over the surfaces for two samples (number of measuring points: 9 per wafer)

\begin{tabular}{|c|c|c|c|}
\hline & & $\mathrm{Fe}$ & $\mathrm{Ni}$ \\
\hline $\begin{array}{l}\text { Batch-1, } \\
\quad \# 20\end{array}$ & $\begin{array}{c}\text { Average concentration/atoms } \mathrm{cm}^{-2} \\
\mathrm{CV} \%\end{array}$ & $\begin{array}{c}5.32 \times 10^{10} \\
9.7\end{array}$ & $\begin{array}{l}1.33 \times 10^{10} \\
22.4\end{array}$ \\
\hline $\begin{array}{l}\text { Batch-2, } \\
\quad \# 25\end{array}$ & $\begin{array}{c}\text { Average concentration/atoms } \mathrm{cm}^{-2} \\
\text { CV \% }\end{array}$ & $\begin{array}{c}4.67 \times 10^{10} \\
9.3\end{array}$ & $\begin{array}{c}1.29 \times 10^{10} \\
18.7\end{array}$ \\
\hline
\end{tabular}

2. Y. Mori, K. Shimanoe, and T. Sakon, Anal. Sci., 1995, 11, 499.

3. Y. Mori and K. Shimanoe, Anal. Sci., 1996, 12, 141.

4. Y. Mori, K. Uemura, K. Shimanoe, and T. Sakon, J. Electrochem. Soc., 1995, 142, 3104.

5. UC Standardization Committee, Ultra Clean Technology, 1996, 8,44

6. Y. Mori, K. Kubota, K. Shimanoe, and T. Sakon, Anal. Sci., 1998, 14, 275.

7. W. Kern and D. A. Puotinen, RCA Rev., 1970, 31, 187.

8. Y. Miyoshi, M. Matsumoto, Y. Dansui, and T. Ohnishi, in Extended Abstracts (The 39th Spring Meeting, 1992) of The Japan Society of Applied Physics and Related Societies, 1992, Narashino, Japan, 692

9. M. Sakurai, J. Ryuta, E. Morita, K. Tanaka, T. Yoshimi, and Y. Shimanuki, in Extended Abstracts of the 177th Electrochemical Society Meeting (PV90-1), 1990, Montreal, Canada, 710 - 711.

10. J. C. Miller and J. N. Miller, "Statistics for Analytical Chemistry", 2nd ed., 1988, Ellis Horwood, Herts, UK (Japanese translation by M. Munemori, ISBN 4-320-042727, is available from Kyoritsu Shuppan, Tokyo, Japan). 